Behavior Genetics, Vol. 22, No. 1, 1992

\title{
Familial Transmission of Alcohol Use: V. Drinking Patterns Among Spouses, Tecumseh, Michigan
}

\author{
Lillian Gleiberman, ${ }^{1,4}$ Ernest Harburg, ${ }^{1,2}$ Wayne DiFranceisco, ${ }^{1}$ and \\ Anthony Schork ${ }^{3}$
}

Received 28 Jan. 1991-Final 7 Sept. 1991

This study examined concordance and discordance of self-reported alcohol consumption in 184 spouse pairs drawn from a representative sample of the Tecumseh, MI community. A significant association (tau $B=.57, \mathrm{p}<.001$ ) between self-reported alcohol consumption of husbands and that of wives was obsenved. Drinking daily and high maximum drinking were also significantly correlated between spouses, as were church attendance, smoking, impulsivity, and sociability. A significant association between the drinking of wives and that of their mothers-inlaw was noted. The relationship between husbands' drinking and that of their fathers-in-law was marginally significant. However, three-quarters of daughters of heavy-drinking fathers (21 of 28) married abstemious men (never drank or drank lightly), while only $7 \%$ married heavy-drinking husbands. These findings lend support to the idea that a network of familial influences-both primary and secondary assortative matingcontributes to regulating adult drinking behavior.

KEY WORDS: assortative mating; alcohol use; familial transmission.

\section{INTRODUCTION}

Previous articles in this series have examined the parental role in the intergenerational transmission of alcohol drinking behavior among nor-

\footnotetext{
${ }^{2}$ Department of Epidemiology, School of Public Health, University of Michigan, Ann Arbor, Michigan 48109.

2 Department of Psychology, University of Michigan, Ann Arbor, Michigan 48109.

${ }^{3}$ Department of Biostatistics, School of Public Health, University of Michigan, Ann Arbor, Michigan 48109.

${ }^{4}$ To whom correspondence should be addressed at Program for Urban Health Research, 307 North $1^{\text {st }}$ Street, Ann Arbor, Michigan 48103.
} 
mal drinkers in Tecumseh, Michigan. Adult offsprings' drinking was found to be significantly related to their parents' drinking 17 years earlier (Webster et al., 1989). On the other hand, nonimitation of parental alcohol use was also observed in a substantial percentage of adult offspring, particularly among those who perceived their cross-sex high-volume drinking parents as having had problems with alcohol (Harburg et al., 1990). The amount of variance in adult offsprings' drinking which was accounted for by parental drinking was modest-9\% for sons and $8 \%$ for daughters. Clearly, significant others from the adult offsprings' own generation such as peers, siblings, and spouses may also exert influences on drinking behavior.

In this paper, we examine assortative mating with respect to alcohol drinking and drinking-related behavior of 184 spouse pairs. Assortative mating is defined as the marriage of people who share certain traits more often than would be expected by chance. Little is known about assortative mating for drinking among normal drinkers. Price and Vandenberg (1980) found evidence for initial assortment as well as for convergence for liquor, wine, and beer consumption. Kolonel and Lee (1981) found correspondence for wine consumption between spouse pairs but little agreement for beer consumption. Buss (1984) reported a significant correlation $(r=.33, p<.001)$ for alcohol drinking in 93 couples.

Assortative mating has been studied in somewhat more depth among alcoholics and their family members (Jacob and Bremer 1986; Hall et al., 1983a,b; McKennan and Pickens 1981). Hall et al. (1983a) found assortative mating for alcohol use to have occurred among the parents of alcoholics. Further, alcoholic subjects with two problem-drinking parents had a high frequency of siblings who were either abstainers (35\%) or problem drinkers (34\%). Hall et al. (1983b) observed that if male alcoholics had problem-drinking mothers, they were more likley to choose either problem-drinking wives $(38 \%)$ or abstinent wives $(38 \%)$, rather than social drinkers $(26 \%)$. There was also a trend for alcoholic wives to marry problem drinkers if their own fathers $(56 \%)$ or mothers $(80 \%)$ had been problem drinkers. This study (Hall et al., 1983b) indicates that among alcoholics, spouse selection, in terms of alcohol drinking, was associated with parental drinking behavior.

The major aim of the present paper is to expand our knowledge of the sources and the impact of assortative mating for alcohol use in a normal drinking sample. We (1) examine concordance and discordance of self-reported alcohol consumption of 184 spouse pairs, (2) explore how respondents' recall of their parents' drinking relates to their own drinking as well as to their spouses' drinking, and (3) examine whether 
similarities/dissimilarities in drinking between spouses have any association with problem drinking in either or both of the spouses.

\section{MATERIALS AND METHODS}

\section{Sample}

The Tecumseh Community Health Study (TCHS) is a longitudinal health investigation begun in 1959 which involved virtually all of the 10,000 residents of the town of Tecumseh, Michigan, and has been described elsewhere (see Napier et al., 1970). In 1977, the Family Health Project used the 1960 TCHS census to obtain a list of multisibling families for the purpose of assembling and sampling family sets. First, a sample of Tecumseh residents was drawn by a random selection of "index" persons from among all the siblings in each family in the census. In addition to the index, the five-member family sets consisted of the spouses of the index (if married), a sibling and a first cousin, both closest in age to the index person, and a randomly selected, genetically unrelated person, who was matched for age and sex to the index (for details on the family set method, see Harburg et al., 1977; Moll et al., 1983). Questionnaires were sent to 2272 individuals identified by the family set process and $74 \%$ were returned ( $N=1672$ total cases). The present subsample consists of the 184 indexes and spouses $(N=368)$ who responded to the questionnaire. The mean $( \pm S D)$ age of the husbands was $41 \pm 11.8$ years (range, 22-71), and the mean age of the wives was $39 \pm 11.0$ years (range, 20-67). The sample of spouses represented the community in being white, of Anglo-Saxon heritage, and of middle income. The modal level of education was high-school completion and $88 \%$ of the sample was married.

\section{Alcohol Consumption}

Self-Report. Respondents were asked 13 alcohol items adapted from Cahalan et al. (1969). Average ethanol consumed (oz/week) was calculated using a slightly modified version of Jessor's (1968) method. The basic method for deriving total ounces of ethanol per week consisted of summing the individual's ethanol intake from beer, wine, and liquor. The amount of ethanol for each component beverage is the product of the number of the number of occasions per week that the person drinks the beverage, the number of units per occasion, and the average ethanol content (constant) for that beverage. One ounce of ethanol equals ap- 
proximately two typical drinks of any alcohol beverage (Gleiberman and Harburg, 1986). The continuous variable of ethanol ounces per week was converted into an approximate number of drinks per week for easier interpretation. Respondents were then placed in one of five categories:

Drinks per week

\begin{tabular}{lcc}
\cline { 2 - 3 } Drinking category & Men & Women \\
\hline Life-long abstainer & 0 & 0 \\
Past drinker & 0 & 0 \\
Low volume & $0-3$ & $0-3$ \\
Medium volume & $>3-<14$ & $>3-<7$ \\
High volume & $\geq 14(2+$ daily $)$ & $\geq(1+$ daily $)$
\end{tabular}

The cutoff points for medium- and high-volume drinking categories differed by sex inasmuch as women compared to men need less alcohol to feel high or drunk. Women absorb alcohol more readily than men because they are generally lighter, they have a higher concentration of body fat, and their overall weight is made up of a smaller proportion of fluid (Mendelson and Mello, 1985). In addition, any community's drinking norms and expectations will differ for men and women, and therefore classification as a low-, medium-, or high-volume drinker is related to these gender-specific norms (Harburg et al., 1980; Klatsky et al., 1983). We emphasize that our classification scheme was not intended to isolate "heavy" or "problem" drinkers. "High volume" in this community is a relative term for men who average two or more drinks per day or for women who average one or more drinks per day. A number of major studies have considered two drinks a day to be "heavier drinking" (e.g., Clark and Midanik, 1982; Malin et al., 1985). Abstainer refers to lifelong abstainer only.

\section{Drinking Label (Self, Spouse, Parents)}

Respondents were also asked to label their own, their spouses', and their parents' drinking habits according to the following categories: never drank, rare or infrequent, light, moderate, heavy, and very heavy drinker. For self and others drinking labels, no separate questions were asked about life-long abstaining or past drinkers and thus the nondrinker category always combines past drinkers and life-long abstainers. Further, the rare or infrequent category was merged with the light, and the heavy/ very heavy categories were also merged and called heavy.

Since the validity of using the respondents' ratings of parents' drinking is of importance, it can be noted that in a different sample of parents 
and offspring, in this project, where parents reported their own consumption of alcohol in 1960 , offsprings' recall was significantly related to this parent self-report. For sons and fathers, $\chi^{2}=168.9, \mathrm{dF}=25$, and $p<.0001$; for daughters and fathers, $\chi^{2}=142.2, \mathrm{dF}=25$, and $p<.0001$ (unpublished data).

\section{Alcohol-Related Behavior}

High- and Low-Maximum Drinking. Two persons may consume similar amounts of alcohol over a period of time but one may drink small quantities on a regular, spaced basis and the other may consume a larger amount on a single, or few, drinking occasion(s). Male spouses were classified as "high-maximum" drinkers if they said they have five or six drinks at a time "nearly every time," "more than half the time," or "less than half the time." The definition of high-maximum drinking for female spouses was extended to include the response "occasionally," as well as all of the above. The same reasons which suggested that we choose different cut points for high-volume drinking for women apply here when choosing criteria for high-maximum drinking.

Number of Drinks Needed to Feel Tipsy. Subjects were asked, "When you drink beer or wine, how many glasses does it take before you first feel it (like getting light-headed, feeling good, very loose, etc.)?" Responses were 1 glass or less, 1-2 glasses, 3-4 glasses, 5-6 glasses, and 7 or more glasses. "When you drink liquor or whiskey, how many shots does it take before you first feel it (like getting light-headed, feeling good, very loose, etc.)?" Responses were takes only 1 shot or less, about 1 or 2,3 or 4,5 or 6 , and 7 or more.

Ever Tried to Quit. Subjects were asked, "Have you ever tried to stop drinking?"' Responses were No, I never tried to stop; Yes, I tried, but did not stop; Yes, I stopped for a while but started again; and Yes, I stopped altogether.

Daily Drinking. Subjects were asked if they drank beer, wine, or liquor regularly, every day. Responses were yes and no.

\section{Personal Behavior Indirectly Related to Alcohol Use}

Smoking. Current smokers were asked, "About how many cigarettes do you usually smoke each day?"' Responses were less than one a day, a few each day, half a pack (more or less), about a pack a day, about a pack and a half, and two or more packs a day.

Church Attendance. Subjects were asked, "How often do you usually attend services?' Responses were 2 times a week or more, once a 
week, 2-3 times a month, about once a month, a few times a year or less, and never attend.

\section{Measures of Emotion}

Subjects answered general psychological measures. These included Eysenck's Neuroticism Scales (Eysenck and Eysenck, 1968) and Buss and Plomin's Impulsivity and Sociability Scale (Buss and Plomin, 1975).

\section{Alcohol-Related Problems}

The Short Michigan Alcoholism Screening Test (SMAST) contains 13 items describing disruptive social consequences from alcohol use (Selzer et al., 1975). We used these items to measure serious social problems related to alcohol use.

A prior factor analysis of the SMAST carried out on 1266 current drinkers (Harburg et al., 1988) yielded five factors: No Problem, Not Normal, Can't Stop Drinking, Family Discord, and Self-Seeking/Conflict. About 5-6\% of the total sample endorsed only the one item for "Can't Stop Drinking" and approximately 90\% of these were males and females who were very light and light drinkers. The Not Normal group (those who endorsed only one or both Not Normal items) was also made up almost entirely of very light and light drinkers. These light social drinkers appear to be reinterpreting the definition of "not normal" as meaning drinking much less than most other people, and not as the item defines "normal": "less or the same as most other people." The Not Normal and Can't Stop groups more closely resemble the No Problem groups with respect to both a psychological adjustment index and an alcohol behavior profile (e.g., tried to quit, drinks daily). Since total ethanol ounces per week of the Not Normal and Can't Stop groups also resembled that of the No Problem group, these three groups were combined and called None/Mild Problems for the present study. All other respondents who endorsed family and work problems or who sought help for their drinking were combined to form the category, Serious Problems.

\section{RESULTS}

Table I indicates that there is a significant association between selfreported alcohol use of husbands and wives (tau $\mathrm{B}=.57, p<.001$ ). The cells along the diagonal indicate that a high proportion of husbands and wives in any given category of drinking behavior tends to be married to each other. By and large, this is true when considered by percentage 


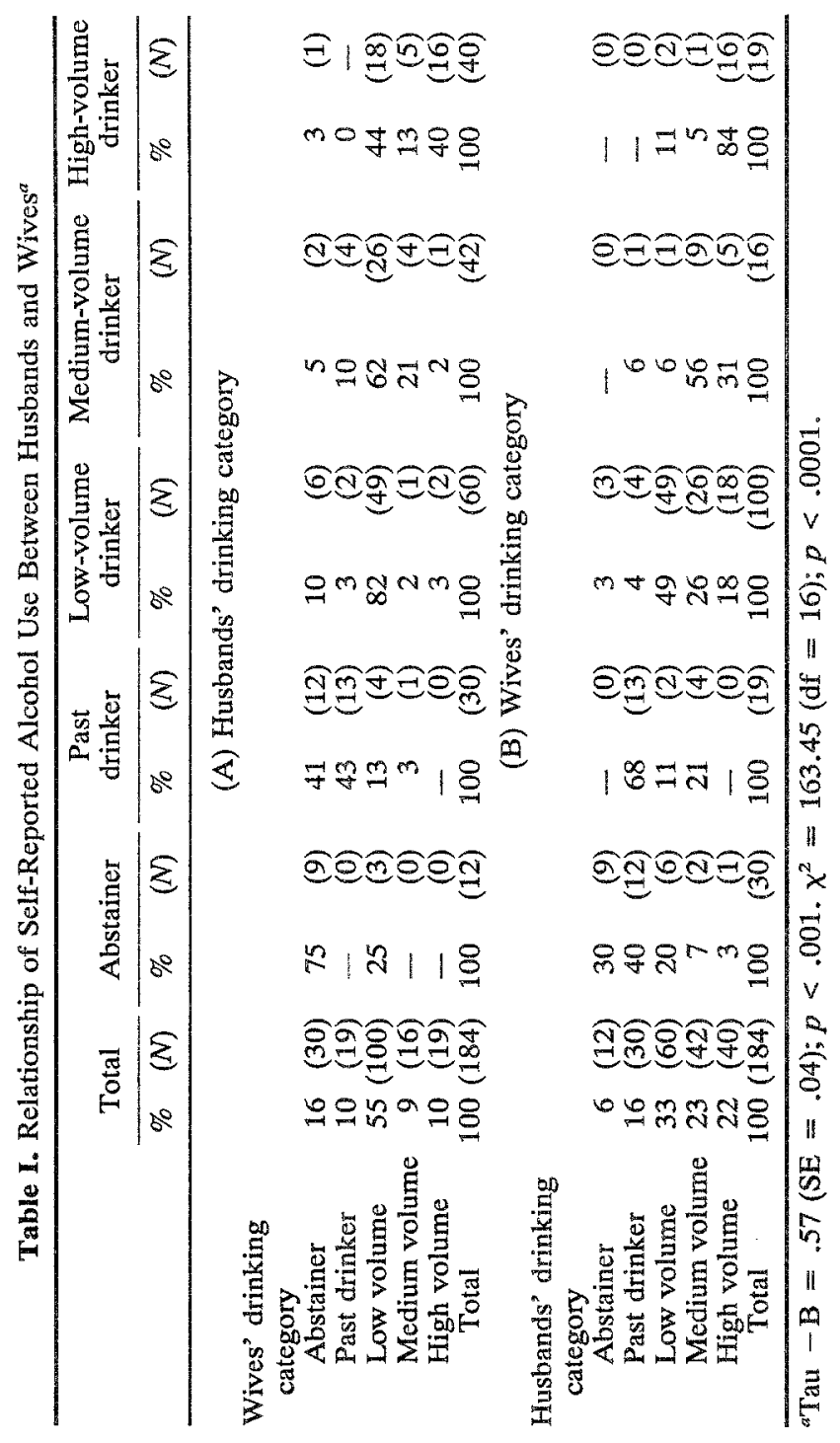


of husbands (Part A) or percentage of wives (Part B). If nondrinkers (past drinkers and abstainers) and low-volume drinkers are considered to be "abstemious" users of alcohol, then the majority of spouse pairs are abstemious ( 98 of 184 , or $53 \%$ ).

The majority of men who abstain tend to be married to abstaining women ( 9 of 12 , or $75 \%$ ), whereas among women who abstain, only $30 \%$ (9 of 30) are married to abstaining men, and the rest are spread across the other categories. In contrast, while $40 \%$ of high-volume men are married to high-volume women, about $84 \%$ (16 of 19) of high-volume women are married to high-volume drinking men. This reflects a general tendency of men to marry women who drink the same or less than they and for women to marry men who drink the same or more. Since the vast majority of women are abstemious, the number of pairs where both husband and wife drink high volume is small in this normal drinking sample (16 of 184 , or $9 \%$ ).

We next examined correlations between spouses for a series of behavioral traits which can be considered (1) descriptive of drinking behaviors other than amount consumed or (2) indirectly related to drinking behavior. In Table II (Part A), we note certain significant similarities in alcohol-related behaviors. Drinking daily and high-maximum drinking were significantly associated between spouses. Table II (Part B) indicates that there was a significant correlation between spouses for the BussPlomin traits of sociability and impulsivity; however, there were no sig-

Table II. Spouse-Pair Similarity for Selected Behavioral Traits

(A) Direct alcohol-related behavior (where both spouses drink; $N=127$ pairs)

\begin{tabular}{lrc}
\hline & \multicolumn{1}{c}{$\chi^{2}$} & $p$ level \\
\hline Ever tried to quit & 2.26 & $\mathrm{NS}$ \\
Drink daily & 27.00 & .0001 \\
Number of drinks to feel tipsy & 0.24 & $\mathrm{NS}$ \\
High-maximum drinking & 8.00 & .004
\end{tabular}

(B) Indirect alcohol-related behavior $(N=184$ pairs $)$

\begin{tabular}{lcc}
\hline & Pearson $r$ & $p$ level \\
\hline Buss-Plomin Sociability & .06 & .03 \\
Buss-Plomin Impulsivity & .17 & .02 \\
Suspect Neuroticsm & .03 & $\mathrm{NS}$ \\
Eysenck Extroversion & .04 & $\mathrm{NS}$ \\
Cigarettes daily & .34 & .0001 \\
Church attendance & .82 & .0001 \\
\hline
\end{tabular}


nificant correlations for the Eysenck Personality traits of neuroticism and extroversion. The highest degree of similarity was noted for smoking behavior and church attendance.

We next assessed whether there were similarities in drinking between the opposite sex parent and the spouse. For this analysis, the husband's drinking labels for his wife and for his mother were used. Table III indicates that there was a significant association between the drinking behavior of wives and that of their mothers-in-law $\left(\chi^{2}=13.8\right.$, $p<.03)$. When self-label of wife was used, results were similar $\left(\chi^{2}=\right.$ $15.0, p<.05$ ). Results also indicate that husbands whose mothers were nondrinkers were more likely to marry nondrinkers than were husbands whose mothers drank. Husbands were also increasingly likely to marry moderate drinkers as their own mothers' drinking level increased. Thus, $6 \%(6 / 97), 13 \%(9 / 71)$, and $29 \%(4 / 14)$ of husbands whose mothers were nondrinkers, light drinkers, and moderate drinkers, respectively, chose moderate drinking spouses.

There were no husbands who labeled their wives heavy and only two who labeled their mothers heavy. Therefore, it was not possible to test whether husbands whose mothers drank heavily tended to marry heavy-drinking wives or seek out abstemious spouses. Interestingly, the two mothers labeled heavy had daughters-in-law who were light drinkers.

Table IV shows a similar analysis for husbands and their fathersin-law, based on the wives' labeling both of their husbands and of their fathers. Here, the relationship is marginally significant $(p=.07)$. Daughters whose fathers never drank were more likely to marry nondrinkers than were daughters of drinking fathers. However, daughters of heavy-drinking fathers were no more likely to marry heavy drinkers than were daughters of the two lower-drinking categories. Three-quarters of the daughters

Table III. Alcohol Use in Female Spouses and Their Mothers-In-Law (Husband Assessed His Wife and His Mother $)^{a}$

\begin{tabular}{|c|c|c|c|c|c|c|c|c|c|c|}
\hline \multirow{3}{*}{$\begin{array}{l}\text { Female spouses } \\
\text { (wives) }\end{array}$} & \multicolumn{10}{|c|}{ Wives' mother-in-law (husbands' mother) } \\
\hline & \multicolumn{2}{|c|}{ Total } & \multicolumn{2}{|c|}{ Nondrinker } & \multicolumn{2}{|c|}{ Light } & \multicolumn{2}{|c|}{ Moderate } & \multicolumn{2}{|c|}{ Heavy } \\
\hline & $\%$ & $(N)$ & $\%$ & $(N)$ & $\%$ & $(N)$ & $\%$ & $\overline{(N)}$ & $\%$ & $(N)$ \\
\hline Nondrinker & 23 & (43) & 31 & (30) & 14 & $(10)$ & 21 & (3) & - & (0) \\
\hline Light & 66 & (122) & 63 & (61) & 73 & $(52)$ & 50 & (7) & 100 & (2) \\
\hline Moderate & 10 & (19) & 6 & (6) & 13 & (9) & 29 & (4) & - & (0) \\
\hline Total & 100 & (184) & 100 & (97) & 100 & (71) & 100 & (14) & 100 & (2) \\
\hline
\end{tabular}

${ }^{a} \chi^{2}=13.8, \mathrm{df}=6, p<.05$. 
Table IV. Alcohol Use in Male Spouses and Their Fathers-in-Law (Wife Assessed Husband and Her Father) ${ }^{a}$

\begin{tabular}{|c|c|c|c|c|c|c|c|c|c|c|}
\hline \multirow{3}{*}{$\begin{array}{l}\text { Male spouses } \\
\text { (husbands) }\end{array}$} & \multicolumn{10}{|c|}{ Husbands' fathers-in-law (wives' father) } \\
\hline & \multicolumn{2}{|c|}{ Total } & \multicolumn{2}{|c|}{ Nondrinker } & \multicolumn{2}{|c|}{ Light } & \multicolumn{2}{|c|}{ Moderate } & \multicolumn{2}{|c|}{ Heavy } \\
\hline & $\%$ & $(N)$ & $\%$ & $(N)$ & $\%$ & $(N)$ & $\%$ & $(N)$ & $\%$ & $(N)$ \\
\hline Nondrinker & 14 & (25) & 38 & (8) & 11 & (12) & 4 & (1) & 14 & (4) \\
\hline Light & 56 & (102) & 43 & (9) & 56 & (58) & 64 & (18) & 61 & (17) \\
\hline Moderate & 24 & (43) & 19 & (4) & 25 & (26) & 29 & (8) & 18 & (5) \\
\hline Heavy & 6 & (11) & - & (0) & 8 & $(8)$ & 4 & (1) & 7 & (2) \\
\hline Total & 100 & $(181)^{b}$ & 100 & (21) & 100 & (104) & 100 & $(28)$ & 100 & $(28)$ \\
\hline
\end{tabular}

${ }^{a} \chi^{2}=15.6, \mathrm{df}=9, p=.07$.

${ }^{b}$ Data missing for three subjects.

Table V. Degree of Similarity of Alcohol Consumption Between Spouses, Spouses and Parents, and Spouses and In-Laws $(N=184)$

\begin{tabular}{lrc}
\hline & $\chi^{2}(\mathrm{df})$ & $p$ level \\
\hline A. $\quad \begin{array}{l}\text { Using husband's self label and wife's self } \\
\text { label }\end{array}$ & $104.9(6)$ & .0001 \\
Husband and wife & & \\
B. $\quad$ Using husband's labels for himself, his wife, & $5.1(6)$ & $\mathrm{NS}$ \\
and his parents & $13.4(6)$ & .03 \\
His father and his wife & $13.6(9)$ & .14 \\
His mother and his wife & $16.3(9)$ & .06 \\
His father and himself & & \\
His mother and himself & $15.6(9)$ & .07 \\
Using wife's labels for herself, her hus- & $7.7(9)$ & $\mathrm{NS}$ \\
band, and her parents & $10.6(6)$ & .10 \\
Her father and her husband & $5.1(6)$ & $\mathrm{NS}$ \\
Her mother and her husband & & \\
Her father and herself & $13.9(9)$ & .13 \\
Her mother and herself & $3.1(9)$ & $\mathrm{NS}$ \\
Using husband/wife labels for themselves & $4.8(6)$ & $\mathrm{NS}$ \\
and spouse labels for in-laws & $15.0(6)$ & .02 \\
Husband and his father-in-law & \\
Husband and his mother-in-law &
\end{tabular}

of heavy-drinking fathers (21 of 28) married "abstemious" men (never drank or drank lightly), while only $7 \%$ married heavy-drinking husbands. In Table $\mathrm{V}$, the degree of similarity in alcohol use of various dyads of the parental and of the offspring generations is examined. In this analysis, spouses' self-label as well as the label they attributed to their 
parents are used. The relationship between husbands and wives, based on their own self labels, is shown as a reference (tau $B=.56, p<$ $.0001)$. The similarity in spouse drinking is clearly the strongest of all combinations and parallels the strong relationship observed when selfreport was used (Table I).

Husbands show a significant relationship to the drinking of their mothers but not to that of their fathers; wives show a borderline relationship to their fathers' drinking and no relationship to their mothers. Wives' drinking is significantly related to that of their mothers-in-law, in the instance where wives label themselves or where their husbands label them. Based on both husbands' self-label and wives' labeling of their husbands, the association between husbands and fathers-in-law is borderline.

In Table VI, we examined the association of shared and nonshared patterns of drinking between spouses on the presence of alcohol-related problems. For this analysis, only spouse pairs wherein both partners drank were examined. The high-volume category for wives in Table VI combined medium-volume and high-volume drinkers. Results differ for husbands and for wives. In Section A of Table VI, which reports the results for husbands, it can be noted that when husbands are high-volume drinkers and their wives are low, $66 \%$ of husbands have serious problems; when both spouses are high-volume drinkers, only $37 \%$ of the husbands have serious problems. Also, in the instance where a husband is low and his wife is high, he is more likely to have problems (maybe binge drinking) than when both are low. For wives (Section $B$ ) we first note that only $11 \%(n=15)$ had serious problems. However, within this small group, the pattern is different than for husbands. When both husbands and wives are high-volume drinkers, $29 \%$ of the wives have serious problems, compared to only $18 \%$ when wives are high-volume drinkers and their spouses are not. Thus, men appear to be protected against problems when their wives accompany them in drinking high volume, whereas women appear more vulnerable to problems when they and their husbands are both high volume. When wives are low volume and their husbands drink high volume, wives have more problems than when both drink low; this is similar to the husbands' pattern.

The possibility that these different proportions of spouses with problems may actually result from differences in alcohol consumption was tested. In Table VI (Part A), husbands' mean alcohol consumption, as normalized ounces per week, is presented. The analyses were carried out with a normalized variable, since the alcohol distribution was L-shaped. An analysis of variance across all groups was significant, as expected. However, there were no significant differences between husbands who 


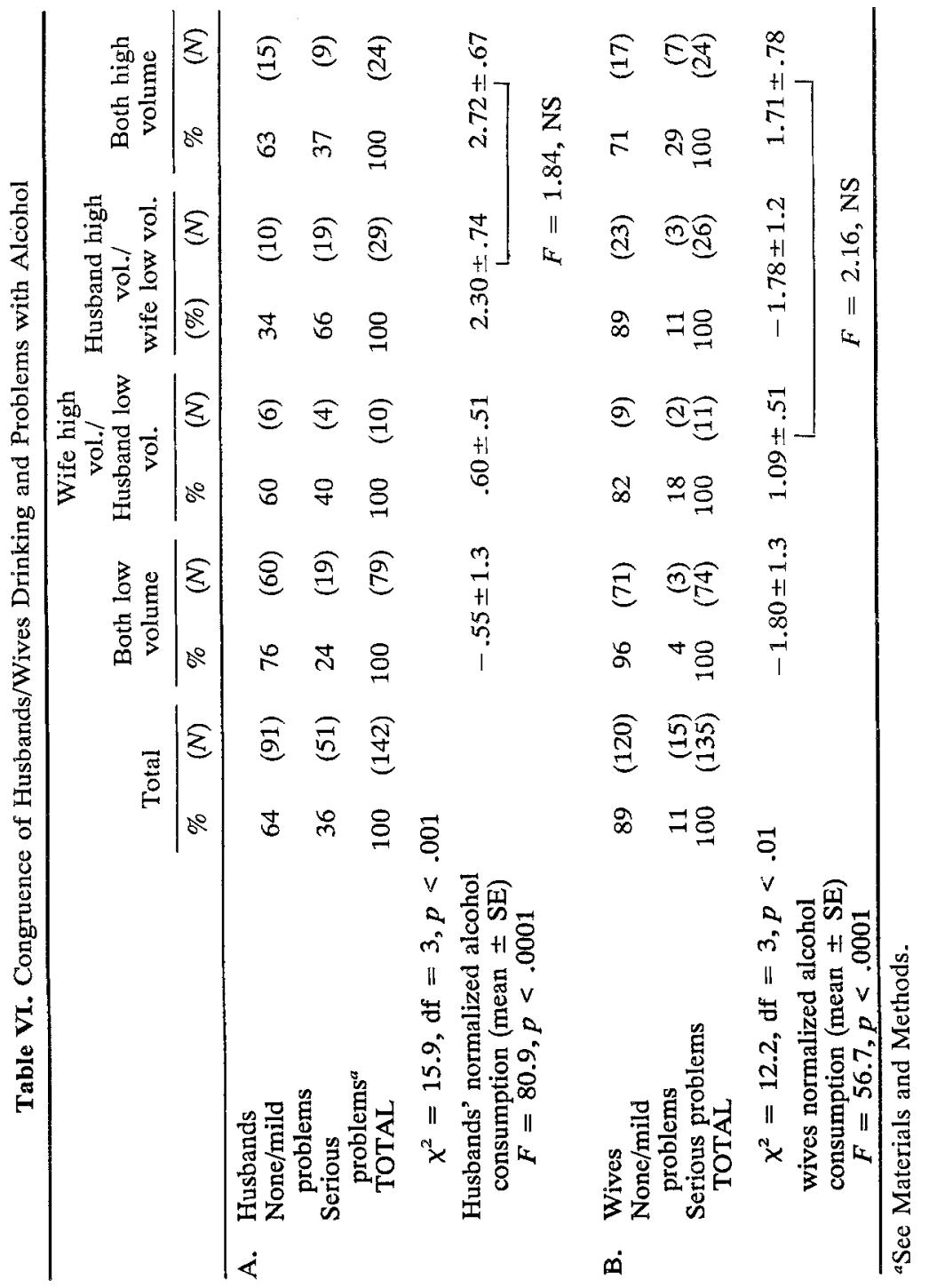


drank high volume (and whose wives drank low volume) and husbands whose wives also drank high volume. We noted that actual alcohol consumption for husbands who drank high volume alone was less $(13.7 \mathrm{oz} /$ wk) than for husbands who drank high volume together with their wives (18.6 oz/wk), thus reinforcing the suggestion that factors other than alcohol quantity are associated with severity of problems.

For wives, Table VI (Part B), significant differences in alcohol consumption were observed across all groups, but no differences were noted between wife high/husband high and wife high/husband low, when using the normalized alcohol variable. Actual alcohol intake for wives was higher among those who drank high volume together with their husbands $(7.5 \mathrm{oz} / \mathrm{wk})$ compared to those who drank high volume alone (3.6 oz/wk). Clinically, if not statistically, these differences may be meaningful and may have an impact on the emergence of problems among high-volume wives who drink with their husbands. The $N$ 's here are low, and the results must be evaluated with caution.

\section{DISCUSSION}

In this study, self-reported alcohol drinking levels of 184 spouse pairs were found to be significantly correlated, confirming findings elsewhere (Price and Vandenburg, 1980; Kolonel and Lee, 1981; Buss, 1984). A number of psychological and behavioral traits-sociability, impulsivity, church attendance, and smoking-were also found to be significantly correlated between spouses. Using the California Personality Inventory, Swan et al. (1986) also found a significant correlation for sociability and self-control in 50 spouse pairs. Similarities with respect to sociability and impulsivity may be indirectly influencing alcohol use. The same can be said of church attendance, which is generally associated with abstemious drinking. We did not find any significant association for Eysenck's extroversion or neuroticism traits. Using this same inventory, Mascie-Taylor and Vandenberg (1988) and Buss (1984) did not find any association for neuroticism, but did find a significant association for extroversion. In this study two other aspects of drinking were also correlated between spouses: daily drinking and high-maximum drinking. To our knowledge, this is the first attempt to examine concordance between spouses for these traits.

The relationship between husbands and wives for alcohol consumption level suggests phenotypic assortative mating. Cloninger (Cloninger et al. , 1979; Cloninger, 1980) divides phenotypic assortative mating into two components, primary and secondary, where primary reflects similarities between spouses and secondary reflects similarities between their 
families. We have observed a significant relationship between a wife's drinking and her mother-in-law and a marginally significant relationship between a husband's drinking and that of his father-in-law. We have also observed a borderline relationship between a spouse and his/her opposite sex parent, but not same sex. This resemblance between spouse and opposite sex parent suggests secondary assortative mating. Burgess and Wallin (1953) have suggested that individuals choose traits in their mates that are present and admired in their opposite-sex parent. Since the drinking behavior of cross-sex parent-offspring pairs has been shown to be associated (Webster et al., 1989), the choice of a spouse who resembles one's opposite sex parent would tend to increase the degree of resemblance between spouses. When parental traits are not admired by the offspring, an aversive effect may occur. For example, we have shown that when fathers are high-volume drinkers with problems, the majority of their daughters tend to be abstemious drinkers (Harburg et al., 1990). This aversive effect could account for the finding in the present study that $75 \%$ of daughters of heavy drinking fathers married abstemious men, i.e., these daughters may have been abstemious drinkers themselves.

Other interpretations can also be offered to account for the findings in this paper. Convergence, for example, cannot be ruled out. This was a cross-sectional study, and thus there was no way to assess the drinking behavior of the spouses at the time of marriage or whether one spouse grew more similar to the other during the course of their marriage. Equally, social homogamy as an explanatory concept, can logically interpret these data. Tecumseh, Michigan, is a strongly homogeneous community; all residents are white, virtually all are Protestants, and class distinctions are weak.

Specific patterns of spouse assortment that we observed may also reflect cultural values. Hall et al. (1983) note that abstinence is not socially valued in men, and thus men abstainers choose mates who are also abstainers, whereas problem drinking males could have mates in any category. Sandmeier (1980) has noted that a greater stigma is associated with being an alcoholic woman, and thus women who abuse alcohol may be restricted in the type of men they can marry. Our data indicated that husbands who were nondrinkers tended to be married to nondrinkers, whereas nondrinking wives had husbands from any category. Heavy-drinking wives were not likely to marry men who drank less than they, but heavy-drinking men appeared to choose wives from any category. These patterns have also been found in a national sample of normal drinkers (Cahalan et al., 1969). Elsewhere in a study of assortative mating among the parents of alcoholics (Hall et al., 1983a), abstinent fathers were highly likely to be married to abstinent mothers, 
but abstinent mothers married across the range of drinking categories. Problem-drinking fathers were found to be married to mothers who drank across the range of drinking categories, but problem-drinking mothers were disproportionately married to problem-drinking fathers.

On the other hand, given the differences in gender norms for drinking levels, these results could also be accounted for by a smaller prevalence of both female high-volume drinkers and male abstainers. Jacob and Bremer (1986) question the contention that assortative mating of male alcoholics occurs at a lower rate than that among women alcoholics. They suggest that the difference is a function of the differences in base rates of alcoholism between the sexes. In other words, because there are fewer female alcoholics, male alcoholics are less likely to be married to one. One beneficial outcome of this differential base rate between the sexes is that there are very few families where both spouses are highvolume drinkers-in our data, only $9 \%$. We have shown elsewhere that when one parent drinks higher and the other low, only $15 \%$ of their sons become high-volume drinkers, compared to $41 \%$ when both parents drink higher volume. Results were similar, but not quite so striking, for daughters (Webster et al., 1989).

Our last finding concerned the effect of shared and nonshared patterns of spouse drinking on the presence of problems associated with alcohol use. We noted that there seemed to be a "protective" effect for high-volume husbands if their wives also drank high volume. Perhaps this correspondence of high-volume drinking between spouses mitigates problems related to family discord for males inasmuch as their wives may be less critical and/or exert less pressure to cut down on drinking. For females, solo high-volume drinking is associated with fewer serious problems than is homogamous high-volume drinking, although, as noted above, the small number of high-volume wives in this sample urges caution in accepting these findings. Only further research will tell if wives who drink high volume alone drink less than those who drink high volume with their husbands.

In sum, this study has shown strong patterns of assortative mating between spouse pairs, as well as some indications that the opposite-sex parents' drinking was associated with one's own drinking and with the drinking of one's spouse. These findings lend support to the idea that a network of familial influences contributes to regulating adult drinking behavior. Both primary and secondary assortative mating may be operating. Despite increases in alcohol consumption during the 1960 s and 1970 s, the modal drinking level in the United States has remained light (Johnson et al., 1977; Klatsky et al., 1983). Familial influences may operate conservatively to constrain the modal drinking level at low vol- 
ume. Indeed, the majority of spouse pairs did drink abstemiously. These sensible drinking levels may be maintained across time, in part, by internalizing community norms transmitted within a family context. However, the above findings, as well as others, need to be investigated in greater depth in future research with larger samples of normal drinkers. We suggest that investigation of assortative mating patterns be included as part of the overall design in studies of the intergenerational transmission of alcohol use.

\section{REFERENCES}

Burgess, E. W., and Wallin, P. (1953). Engagement and Marriage, J. B. Lippincott, Philadelphia.

Buss, D. M. (1984). Marital assortment for personality dispositions: Assessment with three different data sources. Behav. Genet. 14:111-123.

Buss, A. H., and Plomin, R. A. (1975). A Temperament Theory of Personality Development, John Wiley \& Sons, New York.

Cahalan, D., Cisin, I. H., and Crossley, H. M. (1969). American Drinking Practices: A National Study of Drinking Behavior and Attitudes, Rutgers Center of Alcohol Studies Monograph No. 6, New Brunswick, N.J.

Clark, W. B., and Midanik, L. (1982). Alcohol use and alcohol problems among U.S. adults: Results of the 1979 national survey. In Alcohol and Health Monograph No. 1, Alcohol Consumption and Related Problems, National Institute on Alcohol Abuse and Alcoholism, U.S. Government Printing Office, Washington, D.C.

Cloninger, C. R. (1980). Interpretation of intrinsic and extrinsic structural relations by pathanalysis: Theory and applications to assortative mating. Genet. Res. Comb. 36:133-145.

Cloninger, C. R., Rice, J., and Reich, T..(1979). Multifactorial inheritance with cultural transmission and assortative mating. II. A general model of combined polygenic and cultural inheritance. Am. J. Hum. Genet. 31:176-198.

Eysenck, H. J., and Eysenck, S. B. G. (1968). Manual-Eysenck Personality Inventory, Education and Industrial Testing Service, San Diego.

Gleiberman, L., and Harburg, E. (1986). Alcohol usage and blood pressure: A review. Hum. Biol. 58(1):1-31.

Hall, R. L., Hesselbrock, V. M., and Stabenau, J. R. (1983a). Familial distribution of alcohol use. I. Assortative mating in the parents of alcoholics. Behav. Genet. 13:361372.

Hall, R. L., Hesselbrock, V. M., and Stabenau, J. R. (1983b). Familial distribution of alcohol use. II. Assortative mating of alcoholic probands. Behav. Genet. 13:373382.

Harburg, E., Erfurt, J. C., Schull, W. J., Schork, M. A., and Colman, R. (1977). Heredity, stress and blood pressure, a family set method. I. Study aims and sample flow. $J$ Chron. Dis. 30:625-647.

Harburg, E., Ozgoren, F., Hawthorne, V. M., and Schork, M. A. (1980). Community norms of alcohol usage and blood pressure: Tecumseh, Michigan. Am. J. Publ. Hlth. 70:813-820.

Harburg, E., Gunn, R., Gleiberman, L., Roeper, P., DiFranceisco, W., and Caplan, R. (1988). Using the Short Michigan Alcoholism Screening Test to study social drinkers: Tecumseh, Michigan. J. Stud. Alcohol 49:522-531.

Harburg, E,, DeFranceisco, W., Webster, D. W., and Gleiberman, L. (1990). Familial transmission of alcohol use. II. Imitation of and aversion to parent drinking (1960) by adult offspring (1977)-Tecumseh, Michigan. J. Stud. Alcohol 51(3):245-256. 
Jacob, T., and Bremer, D. A. (1986). Assortative mating among men and women alcoholics. J. Stud. Alcohol 47(3):219-222.

Jessor, R. (1968). Society, Personality, and Deviant Behavior: A Study of a Tri-Ethnic Community, Holt, Rinehart and Winston, New York.

Johnson, P., Armor, D. J., Polich, S., and Stambul, H. (1977). U.S. adult drinking practices: Time trends, social correlates, and sex roles. Prepared for National Institute on Alcohol Abuse and Alcoholism, Rand Corp., Santa Monica, Calif.

Klatsky, A. L., Siegelaub, A. B., Landy, C., and Friedman, G. D. (1983). Racial patterns of alcoholic beverage usê.. Alcohol. Clin. Exp. Res. 7(4):372-377.

Kolonel, L. N., and Lee, J. (1981). Husband-wife correspondence in smoking, drinking and dietary habits. Am. J. Clin. Nutr. 34:99-104.

Malin, H. R., Wilson, W., and Williams, C. D. (1985). 1983 NHIS Alcohol/Health Practices Supplement: Preliminary Findings, Proceedings of the 1985 Public Health Conference on Records and Statistics, DHHS PubI. No. (PHS) 86-1214, Public Health Service, Hyattsville, Md.

Mascie-Taylor, C. G. N., and Vandenberg, S. G. (1988). Assortative mating for IQ and personality due to propinquity and personal preference. Behav. Genet. 18:329-345.

McKenna, T., and Pickens, R. (1981). Alcoholic children of alcoholics. J. Stud. Alcohol 42:1021-1029.

Mendelson, J. H., and Mello, N. K. (1985). Alcohol: Use and Abuse in America, Little, Brown, Boston.

Moll, P. P., Harburg, E., Burns, T. L., Schork, M. A., and Ozgoren, F. (1983). Heredity, stress and blood pressure, a family set approach: The Detroit project revisited. J. Chron. Dis. 36:317-328.

Napier, J. A., Johnson, B. C., and Epstein, F. H. (1970). The Tecumseh Community Health Study. In Kessler, L. L., and Leven, M. L. (eds.), Casebook of Community Studies, Johns Hopkins University Press, Baltimore, pp. $25-46$.

Price, R. A., and Vandenberg, S. G. (1980). Spouse similarity in American and Swedish couples. Behav. Genet. 10:59-71.

Sandmaier, M. (1980). The Invisible Alcoholics, McGraw-Hill, New York.

Swan, G. E., Carmelli, D., and Rosenman, R. H. (1986). Spouse-pair similarity on the California Psychological Inventory with reference to husband's coronary heart disease. Psychosom. Med. 48(3/4):172-186.

Selzer, M. L., Vinokur, A., and Van Rooijan, L. A. (1975). A self-administered Short Michigan Alcoholism Screening Test (SMAST). J. Stud. Alcohol 36:117-126.

Webster, D. W., Harburg, E., Gleiberman, L., Schork, M. A., and DiFranceisco, W. (1989). Familial transmission of alcohol use. 1. Parent and adult offspring alcohol use over 17 years-Tecumseh, Michigan. J. Stud. Alcohol. 50(6):557-566.

Edited by H. H. Goldsmith 